\title{
Soilless Cucumber Cultivation under Protective Structures in Relation to Irrigation Coupled Fertigation Management, Economic Viability and Potential Benefits-A Review
}

\author{
Mahesh Chand Singh $^{1 *}$, Dilip Singh Kachwaya ${ }^{2}$ and Kapil Kalsi ${ }^{2}$ \\ ${ }^{1}$ Department of Soil and Water Engineering, Punjab Agricultural University, \\ Ludhiana (PB)-141004, India \\ ${ }^{2}$ Dr. Y S Parmar University of Horticulture and Forestry, Nauni, Solan (HP)-173230, India \\ *Corresponding author
}

\section{A B S T R A C T}

Keywords

Cucumber,

Fertigation, Potential

benefits, Protected

cultivation, Soilless,

Economic viability

Article Info

Accepted:

20 February 2018

Available Online:

10 March 2018

The protected cultivation of cucumber in soilless systems (substrate culture, hydroponic, aeroponic etc.) under optimal operating microclimatic conditions has become an alternative for sustainable vegetable production as a result of shifting climatic scenarios and soil related problems. The soilless cultivation in both open and closed systems with efficient utilization of water and nutrients has significantly increased the greenhouse cucumber productivity compared to conventional cultivation under both protective structures and open field conditions. A closed hydroponic system has helped in saving water and nutrients thereby increasing water and nutrient use efficiency of cucumber cultivation with no environmental pollution. Further, the year round cultivation of cucumber has become possible under protective structures making it as an economically viable technology for the growers. Here, an effort has been made to highlight the progress made in soilless or hydroponic cucumber cultivation in past in relation to irrigation coupled fertigation management, economic viability and the potential benefits. The study also describes the methods for computing the components of water and nutrient use balance in both open and closed systems.

\section{Introduction}

Cucumber (Cucumis sativus L.) is one of the most popular vegetable crops cultivated broadly throughout the world (Soleimani et al., 2009) under plastic greenhouses for higher economic value in off-season cultivation (Chandra et al., 2000). It is thermophilic in nature and frost susceptible crop (Bacci et al., 2006), growing best at a temperature above $22.0^{\circ} \mathrm{C}$ and below $27.0^{\circ} \mathrm{C}$ (Singh et al., 2017a). It grows productively under conditions of high humidity, high light, fertilizers and moisture in plastic greenhouses (El-Aidy et al., 2007). It can be planted by direct seeding or transplanting. The row to row spacing is often kept from 120.0 to 150.0 $\mathrm{cm}$ and plant to plant spacing varies from 30.0 to $45.0 \mathrm{~cm}$. The suitable plant spacing and pruning results in higher fruit yield of 
cucumber (More et al., 1990). Cucumber is cultivated for its tender fruits, which are consumed either raw as salad, cooked as vegetable or pickled in its immature stage (Sumathi et al., 2008). For fresh consumption, cucumber fruits are picked at their full growth stage before attainment of physiological maturity (Kanellis et al., 1986) However, the quality and production of cucumber is now in threat under changing climatic scenarios, growing media (occurrence of soil-borne diseases on global basis) and the microclimate within plant community.

\section{Effect of climate change on crop production}

The climate change which is one of the main determinants of agricultural production has started affecting the pattern of crop growth from last few couple of decades in various agro-climatic zones globally (Wang et al., 2014). The production and quality is affected directly or indirectly due to increased temperature and exposure to elevated levels of carbon dioxide. According to Minaxi et al., (2011), the expected rise in average surface temperature may be in the range of $1.1^{\circ} \mathrm{C}$ $6.4^{\circ} \mathrm{C}$ by the last decade of $21^{\text {st }}$ century on global basis. Any change in climatic factors such as temperature is bound to have a significant impact on crop growth and production (Singh, 2016). In India, climate change has increased the intensity of natural calamities such as floods, droughts, heat waves and cyclones (Goswami et al., 2006). The problems would further aggravate in the years to come due to heavy dependence on agriculture and limited arable land if no corrective measures are taken today. Apart from this, the application of agrochemicals such as fungicide has also limited the production of high value fruits and vegetable crops such as cucumber (Bagi et al., 2014). Numerous factors which affect the cucumber growth and productivity to a significant degree are described in Singh et al., (2017a).

\section{Effect of growing media on crop production}

The major limitations of protective cultivation are soil borne diseases (Baysal-Gurel et al., 2012). The soilless cultivation is therefore, a possible alternative for sustainable vegetable production, which reduces the soil related problems experienced in the conventional crop cultivation (Olympious, 1995; Hussain et al., 2014). Moreover, soilless growing media are easier to handle and may provide a better growing environment compared to soil (Mastouri et al., 2005). Soilless cultivation also offers other benefits such as capability to control water availability, $\mathrm{pH}$ and nutrient concentration in the root zone (Epstein and Bloom, 2005). Cocopeat is one of the soilless media which is suitable for cucumber production. The major limitations of protective cultivation are soil borne diseases (Baysal-Gurel et al., 2012). The soilless cultivation is therefore, a possible alternative for sustainable vegetable production, which reduces the soil related problems experienced in the conventional crop cultivation (Olympious, 1995; Hussain et al., 2014). Moreover, soilless growing media are easier to handle and may provide a better growing environment compared to soil (Mastouri et al., 2005). Soilless cultivation also offers other benefits such as capability to control water availability, $\mathrm{pH}$ and nutrient concentration in the root zone (Epstein and Bloom, 2005). Cocopeat is one of the soilless media which is suitable for cucumber production. The present study was thus undertaken to study the nutrient and water use efficiencies of greenhouse seedless cucumber production in soilless media under partially controlled greenhouse conditions.

The soil borne diseases both in protective structures and open field conditions have limited the cucumber cultivation (BaysalGurel et al., 2012). Under such circumstances, the soilless cultivation can be practiced for 
sustainable vegetable production, with a significant reduction in soil related problems experienced in the conventional cultivation (Olympious, 1995; Hussain et al., 2014). Furthermore, soilless growing systems (substrate culture, hydroponic, aeroponic or aquaponic etc.) may provide a better growing environment and are easier to handle compared to soil (Mastouri et al., 2005). It also offers other benefits such as capability to control $\mathrm{pH}$ and nutrient concentration in the root zone and water availability (Epstein and Bloom, 2005).

\section{Microclimate within plant community}

The productivity of cucumber grown inside protective structure is extremely dependent on light, humidity, temperature, $\mathrm{CO}_{2}$, irrigation water, fertigation, method of cultivation and cultivars. The crop productivity also chiefly depends on the response of plants to environmental conditions. According to Marcelis et al., (2005), the yield of vegetable crops reduces by 0.8-1.0 percent for 1.0 percent reduction of solar radiation reaching the plant canopy. From biomass production and energy saving point of view, an air temperature of $19.0^{\circ} \mathrm{C}$ for daytime and $15.0^{\circ} \mathrm{C}$ for night time and a canopy leaf area index (LAI) of 2.0-3.0 provides the most energy efficient conditions for greenhouse cucumber cultivation under the winter climate conditions (Luo et al., 2005). It is thus important to cultivate cucumbers under protective structures under optimal operating microclimatic conditions for improved yield and quality of fruit.

\section{Protected cultivation}

A protective structure when supported with favorable climatic conditions offers off-season cultivation of vegetable crops which is more profitable in the Northern Plains of India (Nair and Barche 2014). A greenhouse traps solar radiation of short wavelengths to create an encouraging microclimate for plant growth and higher productivity (Tiwari 2006). In the present scenario of continual demand of vegetables and dwindling land holdings drastically, protected cultivation of vegetable crops is also becoming popular in the hilly regions of the country, which offers a great scope for use of low cost naturally-ventilated polyhouses or greenhouses because of mild climate (Mishra et al., 2010). Thus, protected cultivation is now very much needed under Indian conditions to improve the productivity and quality of the vegetable crops (Kohli et al., 2007).

According to Spehia (2015), the productivity of cucumber inside a polyhouse is more than four times of that obtained under open field cultivation. Kumar et al., (2011) reported a 2.5 times increase in vegetable production from 1991-92 to 2010-11 in India. FAO (2011) has reported a cucumber production of 1.60 lakh tonnes with an average productivity of 6412.0 $\mathrm{kg} \mathrm{ha}^{-1}$ from an area of 25104.0 ha in India. The worldwide area under protected cultivation has increased significantly during past couple of decades (Singh et al., 2016). India, from where the cucumber originated is not among the leading global producers. However, the cucumber productivity and fruit quality in soil under protective structures has been significantly reduced due to soil-borne dieases (Hussain et al., 2014). Thus, soilless cultivation can be adopted for sustainable vegetable production.

\section{Soilless cultivation}

The soilless cultivation is a technique of growing crops without soil as rooting media (Savvas et al., 2013). It has been acknowledged internationally due to its ability to maintain efficient and intensive plant production (Barrett et al., 2016). It has become progressively more important 
worldwide during last fifty years (Schmilewski 2009). In recent past, numerous researchers cultivated cucumbers in soilless media under different greenhouse conditions (Huber et al., 2005; Gul et al., 2006; Gul et al., 2007; Janapriya et al., 2010; Zhang et al., 2012; Mazahreh et al., 2015). Subjected to optimal operating microclimatic conditions for greenhouse cucumber cultivation in soilless media (Singh et al., 2017b), desired yield potential of cucumber can be achieved.

\section{Optimal microclimate for cucumber cultivation}

The assemblage of climatological parameters forming around a living plant inside a protective strucutre is termed as greenhouse microclimate (Singh et al., 2016). Thus, it becomes important to maintain the microclimatic parameters to a desired range for better crop growth and productivity through commonly used techniques viz. natural ventilation, shading and evaporative cooling under summer climatic conditions (Singh et al., 2018) and heating in winter climatic conditions. Most recently, Singh et al., (2017b) reported the desirable range for air temperature in plant community, leaf temperature and root-zone temperature as $22.0-27.0^{\circ} \mathrm{C}, \quad 20.5-25.1^{\circ} \mathrm{C}, \quad 16.9-22.9^{\circ} \mathrm{C}$ respectively. According to Singh et al., (2017b), relative humidity, solar radiation and vapour pressure deficit should lie in the range of 60.0-85.0 percent, $100.0-169 \mathrm{Wm}^{-2}$ and $0.53-1.10 \mathrm{kPa}$ respectively for optimal plant growth and development.

\section{Properties of soilless growing media}

The knowledge of physiochemical properties of growing media is essential for limiting them to desired range in order to offer better plant growing conditions. These properties viz. particle density, bullk density, air filled porosity, total porosity, moisture content, field capacity, EC and $\mathrm{pH}$ value can be determined individually by different methods suggested in literature one of which is reported in Verdonck and Gabriels (1992). EC and $\mathrm{pH}$ values are the most sensitive parameters which directly affect the water and nutrient uptake of the plants which in turn can limit the plant growth and development.

Among several growing media, coco-peat is considered as a wonderful growing media with suitable EC, $\mathrm{pH}$ and other chemical properties. Coco-peat has high water holding capacity and its high air filled porosity results in very high seed germination rate and produces more stronger and fibrous seedlings (Fornes et al., 2003). According to Ghehsareh et al., (2011), the water holding capacity (WHC) of cocopeat is 90.5 percent, while other substrates such as perlite and date-palm peat are having WHC of 96.7 percent and 78.3 percent respectively.

\section{Nutrients requirement of cucumber}

The cucumber plants grown in soilless media require a continuous supply of nutrient solution containing both macro and micronutrients in appropriate proportion based on crop growth stage. The elements viz. carbon $(\mathrm{C})$, hydrogen $(\mathrm{H})$ and oxygen $(\mathrm{O})$ are also essentially required by the plants and obtained from water and air. The nutrients (macro) are categorized as primary and secondary macronutrients. The primary macronutrients included nitrogen $(\mathrm{N})$, phosphorus $(\mathrm{P})$ and potassium $(\mathrm{K})$ and the secondary macronutrients included calcium $(\mathrm{Ca})$, magnesium $(\mathrm{Mg})$ and sulphur $(\mathrm{S})$. The micronutrients included boron $(\mathrm{B})$, iron $(\mathrm{Fe})$, manganese $(\mathrm{Mn})$, copper $(\mathrm{Cu})$, zinc $(\mathrm{Zn})$ and molybdenum (Mo). The micronutrients are required by plants in small quantities. The water soluble fertilizers are now easily available in market and can be used as the sources of macro and micronutrients. 


\section{Preparation of nutrient solution}

The nutrient solution can be prepared on daily basis if possible or stock solution (hogland) can be prepared according to literature (Hoagland and Arnon 1950; Sonneveld and Straver 1994). The prepared nutrient solution should be monitored on regular basis for EC, $\mathrm{pH}$ value and deficiency of micronutrients as suggested by Shah et al., (2009).

\section{Disposal of leachate}

Suitable arrangement should be made to safely dispose off the leachate coming out of the growing media in open system. In closed system, the leachate is recirculated and reused causing no environmental pollution.

\section{pH and EC of nutrient solution}

The parameter $\mathrm{pH}$ is directly related to nutrient uptake by plants and should be adjusted to desired range for optimal plant growth. Several chemicals can be used to adjust the $\mathrm{pH}$ of nutrient solutions.

The most popular are phosphoric acid to lower $\mathrm{pH}$ and potassium hydroxide to raise $\mathrm{pH}$. Other chemicals viz. mono potassium phosphate, nitric acid and sulfuric acid can also be used to lower $\mathrm{pH}$. However, nitric acid and sulfuric acid are much more dangerous than phosphoric acid. The $\mathrm{pH}$ value of the nutrient solution should be kept in the range of 6.0-6.40.

On the other hand, the increased EC value of nutrient solution may consequently increase the acidity (Adams and Ho 1989) thereby affecting the crop growth and development. Cucumber is moderately salt-sensitive among the vegetable crops having threshold EC value of $3.0 \mathrm{dS} \mathrm{m}^{-1}$ (Singh et al., 2017a). The preferable EC of nutrient solution is $2.7 \mathrm{dS} \mathrm{m}^{-}$ ${ }^{1}$ and should never exceed $3.0 \mathrm{dS} \mathrm{m}^{-1}$ to avoid the yield penalty (Sonneveld and Voogt 2009). The EC and $\mathrm{pH}$ values of nutrient solution and growing media can be monitored on daily basis using water proof testers.

\section{Method of irrigation coupled fertigation}

Drip irrigation is the most suitable method for irrigating vegetable or fruit crops in both soil and soilless media. It is considered as a tool for increasing water and nutrient use efficiency (NUE) of the crop grown when managed carefully. It maximizes yield with a significant reduction in input water and environmental pollution by improving the photosynthetic capacity of the plants. It minimizes the leaching of nutrients or chemicals from root-zone system of the plants (Gardenas et al., 2005). Numerous studies reported the positive effect of drip irrigation in improving yield of the crop grown (Ertek et al., 2006; Vazquez et al., 2006; Castellanos et al., 2013).

\section{Crop water requirement}

The crop water requirement (CWR) can be estimated from crop transpiration under a closed soilless or hydroponic system. The crop transpiration can be computed using the formula derived from the Penman-Monteith equation (Medrano et al., 2005) with certain modifications in model coefficients (equation 1). Transpiration helps to improve irrigation control in soilless cultivation of crops under greenhouse conditions as it is directly related to plant production (Watts and Goltz 1985). Numerous studies related to transpiration from cucumber crop (evapotranspiration) have been reported in literature (Medrano et al., 2001; Weihong et al., 2004; Medrano et al., 2005; Zhang et al., 2010).

A simplified model derived from PenmanMontheith equation with a few modifications in model coefficients for specific cop and 
climatic conditions can accurately predict the hourly transpiration rate for soilless cucumber crop (Medrano et al., 2001, 2005). Weihong et al., (2004) also computed the canopy transpiration of cucumber crop using PenmanMonteith model. Medrano et al., (2005) evaluated the transpiration time course of cucumber plants cultivated in soilless culture during two cycles at low (up to $9.0 \mathrm{M} \mathrm{J} \mathrm{m}^{-2} \mathrm{~d}^{-}$ ${ }^{1}$ ) and high (up to $20.0 \mathrm{M} \mathrm{J} \mathrm{m}^{-2} \mathrm{~d}^{-1}$ ) radiation levels. Zhang et al., (2010) studied the relationship between crop evapotranspiration $\left(\mathrm{ET}_{\mathrm{c}}\right)$ of cucumber and climatic factors inside a solar greenhouse.

$T=\frac{A \times\left(1-e^{-k \times L A I}\right) \times I_{r a d}+B \times L A I \times V P D}{\lambda}$

Where, $T=$ Crop transpiration $\left(\mathrm{kg} \mathrm{m} \mathrm{m}^{-2} \mathrm{~s}^{-}\right.$ $\left.{ }^{1}\right), I_{\text {rad }}=$ Solar radiation $\left(\mathrm{W} \quad \mathrm{m}^{-2}\right), \quad V P D$ =Vapour pressure deficit $(\mathrm{kPa}), k=$ Extinction coefficient, $L A I=$ Leaf area index $\left(\mathrm{m}^{2} \mathrm{~m}^{-2}\right), \lambda=$ Heat of vaporization of water $(\mathrm{J}$ $\left.\mathrm{kg}^{-1}\right), A=$ Equation parameter (dimensionless) and $B=$ Equation parameter $\left(\mathrm{W} \mathrm{m}^{-2} \mathrm{kPa}^{-1}\right)$

The parameters $A$ and $B$ are different for different seasons.

\section{Fertigation system}

A drip fertigation system generally includes main pipeline, laterals and emitter pipe for supplying nutrient solution to the plants. The system also includes tanks for preparation of nutrient solution, electric motors or solar system, pressure gauges, timers, filters and emitters. The operating pressure of emitters can be regulated using pressure gauge to deliver the nutrient solution safely and at desired rate to the root zone of the plants. The timers allow the application of nutrient solution for a pre-determined time. The nutrient solution should be passed through filters for each supply before its delivery to the plant root system to prevent the clogging of emitters. The nutrient solution is supplied directly to the plants root system through emitters operating at a desired discharge rate.

\section{Computation of water and nutrient balance}

In soilless cultivation, the quantity of nutrient solution applied to the crop on daily basis can be measured by means of measuring cylinders installed at various locations.

\section{Volume of water application}

The total volume ( $V_{\text {nsapp }}$ or $V_{\text {wapp }}$ ) of nutrient solution applied per plant per day in a given time ( $t$ ) can be calculated for a known discharge rate of an emitter using the following relationship.

$V_{\text {wapp }}=n \times q \times t$

Where, $n=$ Total number of emitters operating, $q=$ Emitter discharge (litre $\mathrm{hr}^{-1}$ ) and $t=$ Time to irrigate or fertigate (hr)

If $V_{\text {wupp }}$ and $V_{w d p p}$ be the volume of water uptake and water drained per plant, the water balance can be expressed as $\Delta V_{w s}=V_{\text {wapp }}-V_{\text {wdpp }}-V_{\text {wupp }}$

Where, $V_{\text {wapp }}=$ Volume of water applied per plant (litre plant ${ }^{-1}$ ) and $\Delta V_{w s}=$ Water stored in growing media on volumetric basis.

However for a closed hydroponic system where only plant roots are in contact with running nutrient solution, $\Delta V_{w s}$ can be taken as zero and the equation 4 becomes as $V_{\text {wapp }}-V_{\text {wdpp }}-V_{\text {wupp }}=0$ 


\section{Nutrient balance}

For measurement of leachate coming out of the growing media specially designed trays can be installed at different locations in the experimental trial. The collected leachate or waste nutrient solution can be measured using a measuring cylinder on daily basis and can be recycled for further use in a closed system. Having known the total volume of nutrient solution applied on daily basis and the concentration of each nutrient in the applied nutrient solution, the quantity of applied nutrient to the crop can be computed as $N A_{p p}=c_{a n s} \times V_{\text {nsapp }}$ (5)

Where, ${ }^{T N A_{p p}}=$ Total nutrient applied per plant $\left(\mathrm{mg}\right.$ plant $\left.^{-1}\right),{ }^{C_{a n s}}=$ Concentration of a nutrient in the applied nutrient solution (mg litre ${ }^{-1}$ ) and $V_{n s a p p}=$ Total volume of nutrient solution applied per plant (litre plant ${ }^{-1}$ )

The nutrient concentration of plant can be computed analytically using inductively coupled plasma atomic emission spectroscopy (ICP-AES) except for nitrogen (Grewal et al., 2011). The oven dried samples of leaves, stems and fruits are used for determination of nutrient elements. The concentration of nitrogen present in plant in amonical form can be computed using standard ethods such as Kjeldahl digestion method. The total plant uptake of the nutrient for each element can be computed as $N U_{p p}=c_{L} d w_{L}+c_{S} d w_{S}+c_{F} d w_{F}$

Where, ${ }^{N U_{p p}}=$ Nutrient uptake per plant (mg plant $\left.{ }^{-1}\right), \quad c_{L}=$ Concentration of a nutrient in leaves $(\mathrm{ppm}),{ }^{c_{S}}=$ Concentration of a nutrient in stems $(\mathrm{ppm}),{ }_{F}{ }_{F}=$ Concentration of a nutrient in fruits $(\mathrm{ppm}), d w_{L}=$ Dry weight of leaves $\left(\mathrm{mg} \mathrm{plant}^{-1}\right),{ }^{d w_{S}}=$ Dry weight of stems $\left(\mathrm{mg}\right.$ plant $\left.^{-1}\right), d w_{F}=$ Dry weight of fruits (mg plant $\left.^{-1}\right)$.

The nutrient drained can be computed as $N D_{p p}$ $=N A_{p p}-N U_{p p}$ (7)

Where, $N D_{p p}=$ Total nutrient drained per plant (mg plant ${ }^{-1}$ )

The total nutrient applied, plant uptake and nutrient drained can be computed on per plant and per hectare basis $\left(\mathrm{kg} \mathrm{ha}^{-1}\right)$. The nutrient balance in an open soilless growing media can be expressed as

$\Delta N_{s g m}=N A_{p p}-N U_{p p}-N D_{p p}$

Where, $\Delta N_{s g m}=$ Nutrient storage in growing media (mg plant $\left.{ }^{-1}\right)$

However, the nutrient balance for a closed hydroponic system can be expressed as

$N A_{p p}-N U_{p p}-N D_{p p}=0$

\section{Pollination}

In cucumber, the male flowers emerge first and female flowers shortly later. A female flower contains a small immature fruit at the base while the male flower does not contain any. Pollen is transferred from male to female flower by bees or other insects. After proper pollination the female flower develops into a fruit. However, the parthenocarpic cucumber hybrids produce fruits without pollination. Greenhouse cucumbers are naturally parthenocarpic and the fruits produced are seedless. 


\section{Disease management}

The main entry gate of the greenhouse under experimentation should be provided with an air curtain to create a barrier between outside and inside air and blow away the insects entering the greenhouse during entry of a personal. The insect net (if any) of the greenhouse should be washed with a spray of water under adequate pressure in order to remove insects attached to it before transplanting. The yellow sticky cards can be installed in the whole greenhouse at various locations for controlling the whiteflies incidence to the crop and a spray of Polo (Diafenthiuron $50.0 \%$ WP) can also be done before date of transplanting. The growing media should be disinfected before using it for growing cucumbers next growing season. Fungicides such as Ridomil Gold of Syngenta which is a mixture of systemic and contact fungicide (Metalaxyl-M4.0\%+Mancozeb $64.0 \% \mathrm{WP}$ ) can be used for disinfecting the growing media.

\section{Irrigation coupled fertigation}

Water and nutrients are two vital inputs for plant growth particularly in soilless media and their uptake by plants are two independent processes. Cucumber is considered to be sensitive to drought stress and should never be short of water (Loomis and Crandall 1977) and nutrients. Fertigation in soilless cultivation provides efficient use of water and nutrients (Jensen 1997) through precise and uniform application of nutrients directly to the active root system of the plant (Rouphael et al., 2008). Numerous researchers studied the effect of irrigation amount (Mao et al., 2003; Amer et al., 2009; Salcedo et al., 2017) and fertilizer coupled irrigation i.e. fertigation (Papadopoulos 2001; Lee et al., 2005; Ahmet et al., 2006; Zhang et al., 2011) on cucumber yield and water use efficiency (WUE).
The recommended fertilizers for fertigating cucumbers in soil and soilless systems can be taken from Anon (2018a). The fertigation schedule or nutrients (macro and micro nutrients) required for preparing nutrient solution to fertigate soilless (hydroponic and substrate based) cucumbers can be taken from Anon (2018b) or Anon (2018c) or Papadopoulos (2001).

\section{Water and nutrient use efficiency}

The water use efficiency decreases with increase in irrigation water applied from fruiting to the end of growth stage and increases with increase in irrigation water from cucumber fruit setting to start of fruit ripening (Mao et al., 2003). According to Wang et al., (2009) the IWUE decreased with decrease in water input which also agrees with Ayas and Demirtas (2009). A continous effort has been made in the past to study the effect of irrigation (Sanchez-Guerrero et al., 2009; Grewal et al., 2011) on cucumber growth, yield and quality.

The greenhouse seedless cucumber has a high nutrient requirement and is very productive with adequate supply of nutrients (Sonneveld and Voogt 1978). Drip fertigation allows precise and uniform distribution of water and nutrients exactly to the root system of plant at right time. According to van Os (1999), a soilless system has higher water and nutrient use efficiencies [IWUE or CWUE $=$ yield $(\mathrm{kg}$ plant $\left.{ }^{-1}\right) /$ irrigation water applied $\left(\mathrm{m}^{3}\right.$ plant $\left.^{-1}\right)$ and NUE $=$ yield $\left(\mathrm{kg} \mathrm{plant}^{-1}\right) /$ nutrient applied $\left(\right.$ g plant $\left.^{-1}\right)$ ]. A continous effort has been made in the past to study the effect of fertigation (Gul et al., 2007) on cucumber growth, yield and quality.

While comparing the effect of open and closed systems on cucumbers cultivated in vertical and horizontal bags fertigated with applied and drained nutrient solution, Tuzel et al., 
(1999) confirmed a 22.0 and $35.0 \%$ reduction in water and nutrient consumption under closed system. According to Papadopoulos (2001), the optimal nutrient application to a crop throughout the entire cropping season in relation to changing needs of the plants for nutrients is highly successful due to a greatly improved understanding of plant nutrition and the availability of sophisticated nutrient delivery systems. Huber et al., (2005) cultivated cucumbers in a specially designed urethane based recyclable plant growth substrate (UBS) and rockwool (RW) under a recirculating hydroponic system and confirmed that irrigation was extremely important for crop production with a potential for UBS to evolve as a competitive plant growth substrate for greenhouse soilless crop production with some design modifications. Lee et al., (2005) reported increased plant weight, number of leaves and total yield including marketable yield with increased application of nutrient solution from 0.5 to 2.0 litre plant ${ }^{-1} \mathrm{day}^{-1}$ obtaining highest fruit yields at 1.5 and 2.0 litre plant ${ }^{-1}$ day $^{-1}$ of fertigation level. While evaluating the effect of nutrient sources, organic manure and inorganic conventional nutrient solution on cucumber cultivation in different locally available substrates, Gul et al., (2007) indicated a yield reduction of $10.8 \%$ and $31.3 \%$ under organic nutrient solution and solid organic manure compared to inorganic nutrient solution.

While testing an EC-based irrigation strategy in two greenhouse soilless cucumber crops grown under Mediterranean conditions, Sanchez-Guerrero et al., (2009) concluded that $\mathrm{CO}_{2}$ enrichment combined to an EC-based irrigation scheduling improved the overall water use efficiency of soilless greenhouse cropping systems with a drastic reduction of the leaching fraction. Grewal et al., (2011) confirmed a $33.0 \%$ reduction in potable water used for irrigation in hydroponic cucumber production while investigating the opportunities in recycling drainage water to increase water and nutrient-use efficiency and reduce the environmental impact of the drainage water discharge. Salcedo and Reca (2017) reported a good correlation between the crop water uptake (WU) and the leaf area index (LAI) while evaluating the irrigation water consumption of a soilless cucumber crop under greenhouse conditions under a humid tropical climate in order to improve the irrigation water and fertigation management.

\section{Effect of growing media on nursery raising and fruit quality of cucumber}

Selection of a suitable growing media is extremely important as it influences the quality of seedlings produced. The growing media influences the performance of the ready seedlings before transplanting in the field and the performance of seedlings in the main field after transplanting is evaluated based on their performance in the nursery raising in relation to growing media and microclimatic conditions offered. According to Luoto (1984), the colour of cucumber is affected by growing media at the end of harvest season. The quality of cucumber fruits can be tested by determining texture, colour and taste by either chemical analysis or sensory evaluation (Luoto 1984).

Cucumber contains about $95.2 \%$ water, $1.7 \%$ sugar and $2.8 \mathrm{mg}(100 \mathrm{~g})^{-1}$ vitamin C. Melo et al., (2006) have reported the polyphenol concentration of $9.05 \pm 0.83 \mathrm{mg}(100 \mathrm{~g})^{-1}$ and ascorbic acid concentration of $1.49 \pm 0.85 \mathrm{mg}$ $(100 \mathrm{~g})^{-1}$ in cucumber. Firmness is one of the major quality parameters of pickling cucumbers (Suojala-Ahlfors 2005). However, the transpiration from the cucumber fruits detached from the plants considerably reduces the fruit water content and therefore the fruit firmness. The chlorophyll present in the epidermis is responsible for dark green colour on the surface of cucumber fruit. The 
chlorophyll breakdown results in immediate degreening of cucumber fruit and the exposure of cucumber plants to heat stress during fruit development stage causes bitterness of fruits. The nutritional and calorific value of cucumber is very low, but it is a primary source of vitamins, minerals and fibre for human body. It is also a wonderful source of carbohydrates and phosphorus (Yawalkar 1985).

\section{Soilless cucumber yield}

The cucumber cultivation in soilless system has significantly increased during last couple of decades (Gul et al., 1999; Lorenzo et al., 1999; Tuzel et al., 1999; Huber et al., 2005; Al-Mulla et al., 2008; Janapriya et al., 2010; Zhang et al., 2012; Mazahreh et al., 2015) than soil based cultivation due to occurrence of soil borne diseases. Hickman and Klonsky (1993) reported a yield of $33.0 \mathrm{~kg} \mathrm{~m}^{-2}$ for cucumber cultivated in bag culture inside a greenhouse. Gul et al., (1999) reported no significant difference in plant growth, yield and fruit quality both in open or closed systems while cultivating cucumbers in vertical and horizontal bags containing perlite as growing media in open and closed systems.

However, the plant growth and yield were considerably higher in bags placed horizontally. Lorenzo et al., (1999) obtained a lower yield of cucumber under mulching with white film than conventional soilless culture due to lower temperature of air and growing media in the mulched cucumber during the vegetative development phase, inducing a lower leaf area and LAI thereby reducing the interception of radiation by the cucumbers under mulching.

Al-Mulla et al., (2008) reported higher number of cucumber fruits per plant cultivated in wood straw than date palm straw as growing media. Peyvast et al., (2008) reported a significantly higher fresh weight of cucumber plant grown in peat compared to that in perlite. Alifar et al., (2010) obtained the highest and lowest yield of cucumber fruit from cocopeat and perlite-cocopeat by investigating the effect of five different growing media viz. cocopeat, perlite: cocopeat (50:50), perlite: cocopeat: peatmoss $(50: 20: 30$ and 50:30:20) and perlite: peat moss on volume basis. Janapriya et al., (2010) reported highest yields of $113.9 \mathrm{t} \mathrm{ha}^{-1}$ and $96.1 \mathrm{t} \mathrm{ha}^{-1}$ in greenhouse and open field cultivation of cucumber under the treatment peat: vermicompost: sand with a highest benefitcost ratio of 3.4 with $100.0 \%$ drip fertigation inside the greenhouse.

Ghehsareh et al., (2012) reported higher yield, biomass, plant height, root weight, leaf area index (LAI) and total soluble solids (TSS) of cucumber fruit on using date-palm as growing media compared to the conventional soil system. While evaluating the weathered spent mushroom substrate (SMS) as a growing medium for nursery raising of cucumber, Zhang et al., (2012) indicated a better peroformance of plant height, leaf area, fresh weight, dry weight and seedling quality under SMS: vermiculite of 2:1 and SMS: perlite of 4:1 growing media compared to peat and perlite (1:1). While studying the effect for different growing media viz. perlite (1:0), cocopeat grow bag, perlite: cocopeat $(1: 1)$ and perlite: cocopeat (1:2) on volume basis on cucumber yield, Mazahreh et al., (2015) reported highest $\left(87.6 \mathrm{t} \mathrm{ha}^{-1}\right)$ and lowest (46.0 $\mathrm{t} \mathrm{ha}^{-1}$ ) yield of cucumber under perlite: cocopeat (1:1) and cocopeat grow bag respectively.

\section{Economic feasibility of cucumber cultivation}

The economic viability of cucumber cultivation under protective structures mainly depends on the basic cost of construction of 
the protective structures (Singh and Kumar 2006). The main objective of protective cultivation of vegetable crops including cucumber is to maximize the production through year-round cultivation with improved quality.

Table.1 Benefit cost ratio of cucumber cultivation

\begin{tabular}{|c|c|c|c|c|}
\hline Author & Study site & Growing condition & Variety & $\begin{array}{l}\text { Benefit } \\
\text { cost ratio }\end{array}$ \\
\hline $\begin{array}{l}\text { Singh et al., } \\
\quad(2007 \mathrm{~b})\end{array}$ & $\begin{array}{l}\text { New delhi, } \\
\text { India }\end{array}$ & $\begin{array}{l}\text { Cultivated cucumber } \\
\text { inside a low-cost naturally } \\
\text { ventilated greenhouse }\end{array}$ & $\begin{array}{l}\text { Hasan, } \\
\text { Muhasan } \\
\text { and Sarig }\end{array}$ & 2.3 \\
\hline $\begin{array}{c}\text { Janapriya et al., } \\
(2010)\end{array}$ & $\begin{array}{l}\text { TNAU, } \\
\text { Coimbatore, } \\
\text { India }\end{array}$ & $\begin{array}{l}\text { Grown cucucmber in a mixture } \\
\text { of peat, vermicompost and } \\
\text { sand with } 100.0 \% \text { drip } \\
\text { fertigation inside the } \\
\text { greenhouse }\end{array}$ & $\begin{array}{l}\text { Green } \\
\text { long }\end{array}$ & 3.4 \\
\hline $\begin{array}{l}\text { Mohammadi and } \\
\text { Omid (2010) }\end{array}$ & $\begin{array}{l}\text { Tehran } \\
\text { province of } \\
\text { Iran }\end{array}$ & $\begin{array}{l}\text { Studied the energy balance of } \\
\text { greenhouse cucumber } \\
\text { production by collecting the } \\
\text { data on cucumber production } \\
\text { from fourty three different } \\
\text { greenhouses in the Tehran } \\
\text { province of Iran }\end{array}$ & - & 2.6 \\
\hline $\begin{array}{l}\text { Hakkim and } \\
\text { Chand (2014) }\end{array}$ & $\begin{array}{l}\text { Tavanur, } \\
\text { Kerala, } \\
\text { India }\end{array}$ & $\begin{array}{l}\text { Cultivated cucumber in a } \\
\text { naturally ventilated } \\
\text { greenhouse }\end{array}$ & $\begin{array}{l}\text { hybrid } \\
\text { Hilton F1 }\end{array}$ & 3.4 \\
\hline
\end{tabular}

In past, numerous authors studied the economic feasiiblity of cucumber cultivation in soilless and soil based conditions under protective structures (Engindeniz and Tuzel 2003; Engindeniz 2004; Singh et al., 2007b; Cantliffe et al., 2008; Engindeniz and Gul 2009; Mohammadi and Omid 2010; Garcia et al., 2012; Kumar et al., 2015).

The low-cost naturally ventilated greenhouses are more suitable and economical for yearround cucumber cultivation (Singh et al., 2007b). Cantliffe et al., (2008) gathered relevant information from public, private and research sources to create an economic feasibility model for comparing the costs and benefits associated with field-grown slicing cucumbers and concluded that that it was not only economically feasible to produce cucumbers in a greenhouse setting, but the potential profits were significantly greater for greenhouse-grown cucumbers compared to field-grown cucumbers in Florida.

Engindeniz and Tuzel (2003) reported a net profit of $\$ 1.3 \mathrm{~m}^{-2}$ and $\$ 0.1 \mathrm{~kg}^{-1}$ for cucumbers while evaluating the economic feasibility of cucumber cultivation under farmer's conditions. Engindeniz (2004) evaluated the economic feasibility of growing greenhouse cucumber in soilless culture system. The study emphasized on economic study and benefit-cost analysis at local level and under grower conditions.

According to the study, the net return obtained from greenhouse cucumbers was US $\$ 1.81 \mathrm{~m}^{-2}$ or US $\$ 0.07 \mathrm{~kg}^{-1}$. Engindeniz and Gul (2009) analysed the economic aspects of 
soilless and soil-based greenhouse cucumber production. The study concluded that the net return obtained from cucumbers grown in a mixture of perlite and zeolite was 1.2 times of that in conventional soil-based production. Kumar et al., (2015) reported a higher cost of cultivation of cucumber under polyhouses and net returns by $₹ 185681.00$ and 97138.68 acre $^{-1}$ than open field conditions. The benefit cost ratio of cucumber cultivation under different conditions is reported in Table 1.

\section{Benefits of protective cultivation}

Year round cultivation of cucumbers under protective structures is possible.

Naturally ventilated greenhouses are most suitable for year round cultivation of cucumbers.

It offers distinct advantage of productivity, quality and encouraging market price to the growers.

The productivity of cucumber can be increased manifold as compared to open field cultivation.

Protective cultivation of cucumber minimizes the application of agricultural chemicals.

Reduced consumption of water and nutrients in cucumber production.

\section{Benefits of soilless growing media}

A growing media serves as a reservoir of plant nutrients, anchors the root system and consequently supports the plant.

It significantly affects the seed germination, succeeding emergence, growth and ultimately the quality of seedlings. A substrate that possesses high water holding capacity along with optimum nutrient and aeration for plant growth is advantageous to nursery growers. A better control on plant nutrition and diseases due to better control water on available water, $\mathrm{pH}$ and nutrient concentration in the root zone of plants.

Easier to handle and provide a better growing environment compared to soil.

Reduced intensity of disease occurrence compared to conventional cultivation.

Allows for maximum root growth and support physically the plant.

Increased productivity compared to conventional cultivation or open field conditions.

Saving of water, fertilizer and labour with a significant reduction in insect-pest or disease incidence during continuous cropping and decreased the application of agro-chemicals.

Improved aeration in the root-zone of the plant.

Plants can be moved to a most suited area for better handling whenever required.

The available water per plant is smaller than in soil regardless of the high water holding capacity, low moisture tension and higher hydraulic conductivity for most of the crops grown in the substrates.

No environmental pollution in closed hydroponic system.

\section{Factors limiting cucumber cultivation}

Changing climate scenarios.

Inappropriate plant microclimate.

Prevalence of soil borne diseases. 
Growing media and nutritional deficiency (calcium, iron and manganese) or excess.

Toxicity occurrence in the crop due to excess of nutrients applied.

Occurrence of whiteflies incidence, mite and fungal diseases.

Senstivity to draught or water stress.

Sensitivity to salt.

$\mathrm{EC}$ and $\mathrm{pH}$ of nutrient solution and growing media.

\section{Safety measures}

The frequent entry to the protective structure where the nursery is raised or crop is grown should be avoided.

While handling the plants such as thinning of plants, hands should be covered with gloves.

Check for incidence of insect-pest incidence (if any) on regular basis.

Check for any leakage in the protective structure through cover which may allow the entry of insects.

Incidence of whiteflies is very common while growing nurseries for cucumber even under protective structures. Primarily, sticky trap cards can be installed inside the structure in plant community.

For controlling incidence of insect-pest or diseases, the insecticide used should be in desired quantity since the overdose may harm the plants.

Fertilizers should also be applied in right amount for not to encourage incidence of diseases.
Irrigate the nursery plants according to the need only.

Allow sufficient ventilation for air exchange between inside and outside of protective structure. However, the higher ventilation rate may significantly raise the inside air temperature.

Sufficient light should be allowed to enter the structure which is essentially required by the plant for its growth and hardening of the plant stem.

Allow partial shading to the plants in the nursery.

Do thinning of the plants in nursery for improved aeration between the plants.

Treat the growing media for repeated use to prevent it from fungal diseases if any.

Temperature and relative humidity are two main parameters on which the performance of cucumber depends to a significant extent and should be maintained to optimum range.

The other factors such as level of $\mathrm{CO}_{2}$, PAR and VPD may also be monitored and maintained to desired range if possible.

During warm climates, when temperature goes out of control even in the presence of a shade net at a certain height inside the structure, a shade net may also be installed outside the structure at desired location to reduce the unwanted radiation entering the structure. Doing this may significantly reduce the inside air temperature and maintain optimum microclimate.

The protected cultivation of cucumber in both open and closed soilless systems with efficient utilization of water and nutrients can support the sustainable vegetable production 
worldwide with no environmental pollution. The possibility of year round cultivation (thrice a year) of cucumber in soilless or hydroponic system under a protective structure may attract the growers to increase their productivity compared to cost of cultivation and making it as an economically feasible technique. Thus, in countries like India, with existing subsidies (given by state and central governments), the soilless cultivation of cucumber under protective structures may offer multiple benefits to the growers.

\section{References}

Adams P, Ho L C. 1989. Effects of constant and fluctuating salinity on the yield, quality and calcium status of tomatoes. Journal of Horticultural Sciences, 64, 725-732.

Ahmet E, Suat S, Ibrahim G, Cenk K. 2006. Irrigation scheduling based on pan evaporation values for cucumber (Cucumis sativus L.) grown under field conditions. Agricultural Water Management, 81, 159172.

Alifar N, Ghehsareh A M, Honarjoo N. 2010. The effect of growth media on cucumber yield and its uptake of some nutrient elements in soilless culture. Journal of Science and Technology, 1, 19-25.

Al-Mulla Y A, Al-Balushi M, Al-Rawahy M, AlRaisy F, Al-Makhmary S. 2008. Screenhouse microclimate effects on cucumber production planted in soilless culture (open system). Acta Horticulturae, 801, 637-647.

Amer K H, Midan S A, Hatfield J L. 2009. Effect of deficit irrigation and fertilization on cucumber. Agronomy Journal, 101, 15561564.

Anonymous (2018a). http://www.haifa group.com/knowledge_center/recommendat ions/vegetables /fertilization_of_cucumber_ in_various_growing_methods.aspx [accessed on 22/02/2018]

Anonymous (2018b). https://www.wur.nl/ upload_ $\mathrm{mm} / 8 / \mathrm{c} / 0 / \mathrm{aa} 4 \mathrm{~b} 4486-\mathrm{a} 9 \mathrm{db}-429 \mathrm{f}-$ $8 \mathrm{~b} 03$ f19d4cec3ee6
Fertigation $\% 20$ and $\% 20$

Substrate\%20Management\%20in\%20Close $\mathrm{d} \% 20$ Soilless\%20Culture.pdf [accessed on 22/02/2018]

Anonymous (2018c). http://www.haifagroup.com/files/Guides/Cucumber.pdf [accessed on 22/02/2018]

Anonymous (2018d). http://publications.gc.ca/ collections/collection_2013/aacaafc/agrhist/A53-1562-1975-eng.pdf

Bacci L, Pianco M C, Gonring A H R, Guedes R N C, Crespo A L B. 2006. Critical yield components and key loss factors of tropical cucumber crops. Crop Protection, 25, 1117-1125.

Bagi F F, Budakov D B, Bursic V P, Stojsin V B, Lazic S D, Vukovic S M. 2014. Efficacy of azoxystrobin for the control of cucumber downy mildew (Pseudoperonospora cubensis) and fungicide residue analysis. Crop Protection, 61, 74-78.

Barrett G E, Alexander P D, Robinson J S, Bragg N C. 2016. Achieving environmentally sustainable growing media for soilless plant cultivation systems-A review. Scientia Horticulturae, 212, 220-234.

Cantliffe D J, Webb J E, Vansickle J J, Shaw N L. 2008. The economic feasibility of greenhouse-grown cucumbers as an alternative to field production in Northcentral Florida benefit-cost analysis. Proceedings

Florida State Horticultural Society, 121, 222-227.

Castellanos M T, Tarquis A M, Ribas F, Cabello M J, Arce A, Cartagena M C. 2013. Nitrogen fertigation: An integrated agronomic and environmental study. Agricultural Water Management, 120, 4655.

Chandra P, Sirohi P S, Behera T K, Singh A K. 2000. Cultivating vegetables in polyhouse. Indian Journal of Horticulture, 45, 17-25.

El-Aidy F, El-Zawely A, Hassan N, El-Sawy M. 2007. Effect of plastic tunnel size on production of cucumber in delta of Egypt. Applied Ecology and Environmental Research, 5, 11-24.

Engindeniz S, Gul A. 2009. Economic analysis of soilless and soil-based greenhouse 
cucumber production in turkey. Scientia Agricola (Piracicaba, Braz.), 66, 606-614.

Engindeniz S, Tuzel Y. 2003. Comparative economic analysis of organic tomato and cucumber production in greenhouse: the case of Turkey. Acta Horticulturae, 614, 843-848.

Engindeniz S. 2004. The economic analysis of growing greenhouse cucumber with soilless culture system: The case of Turkey. Journal of Sustainable Agriculture, 23, 5-19.

Ertek A, Sensoy S, Gedik I, Kucukyumuk C. 2006. Irrigation scheduling based on pan evaporation values for cucumber (Cucumis sativus L.) grown under field conditions. Agricultural Water Management, 81, 159172.

FAO. 2011. Current World Agriculture Production 2011-2012. Food and Agricultural Organization of the United Nations, Rome.

Fornes F, Belda R M, Abad M, Noguera P, Puchades R, Maquieira A, Noguera V. 2003. The microstructure of coconut coir dusts for use as alternatives to peat in soilless growth media. Australian Journal of Experimental Agriculture, 43, 11711179.

Garcia M C, Belmonte A, Pascual F, Garcia T, Simon A, Segura ML, Martin G, Janssen D, Cuadrado I M. 2012. Economic evaluation of cucumber and French bean production: comparing integrated and organic crop production management. Acta Horticulturae, 930, 115-120.

Gardenas A I, Hopman J W, Hanson B R, Simunek J. 2005. Two dimensional modelling of nitrate leaching for various fertigation scenarios under micro irrigation. Agricultural Water Management, 74, 219242.

Ghehsareh A M, Hematian M, Kalbasi M. 2012. Comparison of datepalm wastes and perlite as culture substrates on growing indices in greenhouse cucumber. International Journal of Recycling of Organic Waste in Agriculture, 1, 5.

Ghehsareh A M, Samadi N, Borji H. 2011. Comparison of date-palm wastes and perlite as growth substrates on some tomato growing indexes. African Journal of Biotechnology, 10, 4871-4878.

Goswami B N, Venugopal V, Sengupta D, Madhusoodanan M S, Xavier Prince K. 2006. Increasing trend of extreme rain events over India in a warming environment. Science, 314, 1442-1445.

Grewal H S, Maheshwari B, Parks S E. 2011. Water and nutrient use efficiency of a lowcost hydroponic greenhouse for a cucumber crop: An Australian case study. Agricultural Water Management, 98, 841846.

Gul A, Engindeniz S, Aykut N. 2007. Can closed substrate culture be an alternative for smallscale farmers? Acta Horticulturae, 747, 8389.

Gul A, Engindeniz S, Eltez RZ, Aykut N, Gulcin H. 2006. Adaptation of closed substrate culture by small-scale farmers. Acta Horticulturae, 729, 261-266.

Gul A, Tuzel I H, Tuncay O, Eltez R Z, Zencirkiran E. 1999. Soilless culture of cucumber in glasshouses: I. A comparison of open and closed systems on growth, yield and quality. Acta Horticulturae, 491, 389-394.

Hakkim V M A, Chand A R J. 2014. Effect of drip irrigation levels on yield of salad cucumber under naturally ventilated polyhouse. IOSR Journal of Engineering, 04, 18-21.

Hickman G W, Klonsky K. 1993. Greenhouse cucumbers-bag culture: cost of production and equipment in San Joaquin Valley, Stockton: University of California, p.4.

Hoagland D R, Arnon D I. 1950. The water culture method for growing plants without soil. Agric. California Agricultural Experiment Station Circulation, 347, pp 39.

Huber J J, Zheng Y, Dixon M A. 2005. Hydroponic cucumber production using urethane foam as a growth substrate. Acta Horticulturae, 697, 139-145.

Hussain A, Iqbal K, Aziem S, Mahato P, Negi A K. 2014. A review on the science of growing crop without soil (soilless culture) a novel alternative for growing crops. International Journal of Agriculture and $\mathrm{Cr}$ op Sciences, 7, 833-842. 
Janapriya S, Palanisamy D, Ranghaswami M V. 2010. Soilless media and fertigation for naturally ventilated polyhouse production of cucumber (Cucumis sativus L.) cv green long. IJAEB (Agronomy, 3, 199-205.

Jensen M H. 1997. Hydroponics. HortScience, 32, 1018-1021.

Kanellis A K, Morris L L, Saltveit M E. 1986. Effect of stage of development on postharvest behavior of cucumber fruit. HortScience, 21, 1165-1167.

Kohli U K, Kumar M, Dohroo N P, Sharma K C. 2007. Growing media and substrate. In: Protected cultivation of vegetable crops, CAS in Horticulture (Vegetables). pp 3740. Dr. YSPUH\&F- Nauni, Solan, Himachal Pradesh.

Kumar B, Mistry N C, Chander B S, Gandhi P. 2011. Indian horticulture production at a glance. Indian Horticulture Database-2011. NHB, Ministry of Agriculture, Government of India.

Kumar P, Chauhan R S, Grover R K. 2015. Comparative economics of cucumber cultivation under polyhouses and open field conditions in Haryana. Indian Journal of Economics and Development, 3, 1-4

Lee J H, Park S K, Lee Y H, Lee Y B. 2005. Effect of fertigation level and frequency on uptake of nutrients, growth and yield in cucumber. Journal of Korean Society for Horticultural Science, 46, 356-362.

Loomis E L, Crandall P C. 1977. Water consumption of cucumbers during vegetative and reproductive stages of growth. Journal of American Society for Horticultural Science, 102, 124-127.

Lorenzo P, Sanchez-Guerrero M C, Medrano E, Perez J, Castilla N. 1999. Soilless cucumber response to mulching in an unheated mediterranean greenhouse. Acta Horticulturae, 491, 401-404.

Luo W, de Zwart H F, Dai I J, Wang X, Stanghellini C, Bu C. 2005. Simulation of greenhouse management in the Subtropics, Part I: Model validation and scenario study for the winter season. Biosystem Engineering, 90, 307-318.

Luoto L. 1984. Effects of growing media on the postharvest quality of tomatoes and cucumbers. Acta Horticulturae, 163, 237244.

Mao X S, Liu M Y, Wang X Y, Liu C M, Hou Z M, Shi J Z. 2003. Effects of deficit irrigation on yield and water use of greenhouse grown cucumber in the North China plain. Agricultural Water Management, 61, 219-228.

Marcelis L F M, Broekhuijsen A G M, Meinen E. 2005. New look at 1.0 percent rule of thumb. Fruit and Vegetable Technology, 5, 25-26.

Mazahreh N, Nejatian A, Mousa M. 2015. Effect of different growing medias on cucumber production and water productivity in soilless culture under UAE conditions. Merit Research Journals of Agricultural Science and Soil Science, 3, 131-138.

Medrano E, Lorenzo P, Sanchez-Guerrero M C, Montero J I. 2005. Evaluation and modelling of greenhouse cucumber-crop transpiration under high and low radiation conditions. Scientia Horticulturae, 105, 163-175.

Medrano E, Lorenzo P, Sanchez-Guerrero M C. 2001. Evaluation of a greenhouse crop transpiration model with cucumber under high radiation conditions. Acta Horticulturae, 559, 465-470.

Melo E de A, Lima VLAG de, Maciel M I S, Caetano A C da S, Leal F L L. 2006. Polyphenol, ascorbic acid and total carotenoid contents in common fruits and vegetables. Brazilian Journal of Food Technology, 9, 89-94.

Minaxi R P, Acharya K O, Nawale S. 2011. Impact of climate change on food security. International Journal of Agriculture, Environment and Biotechnology, 4, 125127.

Mishra G P, Singh N, Kumar H, Singh S B. 2010. Protected cultivation for food and nutritional security at Ladakh. Defence Science Journal, 61, 219-225.

Mohammadi A, Omid M. 2010. Economical analysis and relation between energy inputs and yield of greenhouse cucumber production in Iran. Applied Energy, 87, 191-196. 
More T A, Chandra P, Singh J K. 1990. Cultivation of cucumber (Cucumis sativus L.) in greenhouse during winter of North India. Indian Journal Agricultural Sciences, 60, 356-357.

Nair R, Barche S. 2014. Protected cultivation of vegetables-present status and future prospects in India. Horticulture, 4, 245-247.

Papadopoulos A P. 2001. Computerized fertigation for cucumber production in soil and in soilless media. Acta Horticulturae, 548, 115-124.

Peyvast G H, Noorizadeh M, Hamidghli J, Ramezani-Kharazi P. 2008. Effects of four different substrates on growth, yield and some fruit quality parameters of cucumber in bag culture. Acta Horticulturae, 779, 535-540.

Rouphael Y, Cardarelli M, Rea E, Colla G. 2008. The influence of irrigation system and nutrient solution concentration on potted geranium production under various conditions of radiation and temperature. Scientia Horticulturae, 118, 328-337.

Salcedo G A, Reca J. 2017. Irrigation water consumption modelling of a soilless cucumber crop under specific greenhouse conditions in a humid tropical climate. Ciencia Rural, 47, 1-9.

Sanchez-Guerrero M C, Lorenzo P, Medrano E, Baille A, Castilla N. 2009. Effects of ECbased irrigation scheduling and $\mathrm{CO}_{2}$ enrichment on water use efficiency of a greenhouse cucumber crop. Agricultural Water Management, 96, 429-436.

Savvas D, Gianquinto G, Tuzel Y, Gruda N. 2013. Soilless culture. Good agricultural practices for greenhouse vegetable crops, principles for Mediterranean climate areas, 217. FAO plant production and protection paper, $\mathrm{pp}$. 303-54.

Schmilewski G. 2009. Growing media constituents in the EU. Acta Horticulturae, 819, 33-45.

Shah A H, Muhammad S, Noor-UL-Amin, Wazir F K, Shah S H. 2009. Comparison of two nutrient solution recipes for growing cucumbers in a non- circulating hydroponic system. Sarhad Journal of Agriculture, 25, 179-186.
Singh B, Kumar M, Sirohi N P S. 2007a. Protected cultivation of cucurbits under low-cost protected structures: a sustainable technology for peri-urban areas of northern India. Acta Horticulturae, 731, 267-272.

Singh B, Kumar M, Sirohi N P S. 2007b. Technoeconomic feasibility of year-round parthenocarpic cucumber cultivation under naturally ventilated greenhouse in northern India. Acta Horticulturae, 731, 277-280.

Singh M C, Singh J P, Pandey S K, Mahay D, Srivastava V. 2017a. Factors affecting the performance of greenhouse cucumber cultivation-a review. International Journal of Current Microbiology and Appled Sciences, 6, 2304-2323.

Singh M C, Singh J P, Pandey S K, Nikhil G C, Sharma P, Shrivastav V, Sharma P. 2018. A review of three commonly used techniques of controlling greenhouse microclimate. Journal of Current Microbiology and Appled Sciences, 7, 3491-3505.

Singh M C, Singh J P, Singh K G. 2017b. Optimal operating microclimatic conditions for drip fertigated cucumbers in soilless media under a naturally ventilated greenhouse. Indian Journal of Ecology, 44, 821-826.

Singh M C. 2016. Possible futuristic rainfall and temperature variability trend in central Indian Punjab. Res Environ Life Sci 9:10004.

Singh M C, Yousuf A, Singh J P. 2016. Greenhouse microclimate modeling under cropped conditions-A review. Research in Environment and Life Sciences, 9, 15521557.

Soleimani A, Ahmadikhah A, Soleimani S. 2009. Performance of different greenhouse cucumber cultivars (Cucumis sativus L.) in southern Iran. African Journal of Biotechnology, 8, 4077-4083.

Sonneveld C, Straver N. 1994. Nutrient solutions for Vegetables and Flowers grown in water or substrates. Research Station for Floriculture and Glasshouse Vegetables, Aalsmeer/Naaldwijk, The Netherlands, Series: Voedingsoplossingen Glastuinbouw, 8, pp 45.

Sonneveld C, Voogt S J. 1978. Effects of saline irrigation water on glasshouse cucumbers. Plant and Soil, 49, 595-606. 
Sonneveld C, Voogt W. 2009. Plant nutrition of greenhouse crops. Springer, Dordrecht, Heidelberg, London, New York. pp 431.

Spehia R S. 2015. Status and impact of protected cultivation in Himachal Pradesh, India. Current Science, 108, 2254-2257.

Sumathi T, Ponnuswami V, Selvi B S. 2008. Anatomical changes of cucumber (Cucumis Sativus L.) leaves and roots as influenced by shade and fertigation. Research journal of agriculture and biological sciences, 4, 630-638.

Suojala-Ahlfors T. 2005. Fruit firmness of pickling cucumber cultivars. HortTechnolology, 15, 777-781.

Tiwari G N. 2006. Greenhouse Technology for Controlled Environment. Pp 21-25. NarosaPublication house, New Delhi.

Tuzel I H, Irget M E, Gul A, Tuncay O, Eltez R Z. 1999. Soilless culture of cucumber in Glasshouses-II. A comparison of open and closed systems on water and nutrient consumption. Acta Horticulturae, 491, 395400.

Van Os E. 1999. Closed soilless growing systems: a sustainable solution for Dutch greenhouse horticulture. Water Science and Technology, 39, 105-112.

Vazquez N, Pardo A, Suso M L, Quemada M. 2006. Drainage and nitrate leaching under processing tomato growth with drip irrigation and plastic mulching. Agriculture, Ecosystems and Environment, 112, 313323.

Verdonck O, Gabriels R. 1992. Reference method for the determination of physical properties of plant substrates. II. Reference method for the determination of chemical properties of plant substrates. Acta Horticulturae, 302, 169-179.

Wang Z, Liu Z, Zhangand Z, Liu X. 2009. Sub surface drip irrigation scheduling for cucumber (Cucumis sativus L.) grown in solar greenhouse based on $20 \mathrm{~cm}$ standard pan evaporation in Northeast China. Scientia Horticulturae, 123, 51-57.

Weihong L, Xiaohan W, Jianfeng D, Weimin D, Shirong G, Shijun L. 2004. Measurement and simulation of cucumber canopy transpiration in a subtropical modern greenhouse under winter climate conditions. Acta Phytoecol Sinica, 28, 5965.

Yawalkar K S. 1985. Vegetable Crops of India. Agri-Horticultural Publishing House, Nagpur.

Zhang H X, Chi D C, Wang Q, Fang J, Fang X Y. 2011. Yield and quality response of cucumber to irrigation and nitrogen fertilization under subsurface drip irrigation in solar greenhouse. Agricultural Sciences in China, 10, 921-930.

Zhang R H, Duan Z Q, Li Z G. 2012. Use of spent mushroom substrate as growing media for tomato and cucumber seedlings. Pedosphere, 22, 333-342.

Zhang Z, Liu S, Liu S, Huang Z. 2010. Estimation of cucumber evapotranspiration in solar greenhouse in northeast China. Agricultural Sciences in China, 9, 512-518.

\section{How to cite this article:}

Mahesh Chand Singh, Dilip Singh Kachwaya and Kapil Kalsi. 2018. Soilless Cucumber Cultivation under Protective Structures in Relation to Irrigation Coupled Fertigation Management, Economic Viability and Potential Benefits - A Review. Int.J.Curr.Microbiol.App.Sci. 7(03): 2451-2468. doi: https://doi.org/10.20546/ijcmas.2018.703.286 